Rurali: Revista interdisciplinar de estudios rurales, N. 1, V.1, enero a junio de 2021, pp.24-27

Doi: https://doi.org/10.7203/Rurali.1.1.17613

\title{
Una herramienta para el empoderamiento rural. Intervención en políticas públicas desde la perspectiva de "La ciudad educadora"
}

\section{Cristina Benlloch Domènech ${ }^{1}$}

La herramienta que se presenta es la «Ciudad Educadora», una forma de entender la dinámica los asentamientos poblacionales. Es conveniente desarrollar políticas públicas en los contextos rurales desde esta perspectiva porque parten de un concepto de educación transversal y de ciudadanía activa que pueden ser una forma de empoderamiento de los contextos. Y esto es posible gracias a la Ciudad Educadora, porque comprende que estos están llenos de posibilidades y herramientas educativas si se dirigen a ello.

Aunque hablemos de Ciudad Educadora, esta forma de trabajar sobre la educación y las políticas públicas se dirige tanto a los municipios más grandes como a los más pequeños (tanto rurales como urbanos). El requisito para formar parte de este colectivo es entender la educación desde una perspectiva holística e integradora.

Para conocer pormenorizadamente qué es una Ciudad Educadora es necesario dirigirse a la Carta de Ciudades Educadoras. Esta fue una iniciativa creada en el I Congreso Internacional de Ciudades Educadoras de Barcelona en 1990. El objetivo con que se creó es que las ciudades no pueden dejar al azar la educación. Como se ha mencionado, para ser Ciudad Educadora, las poblaciones pueden adherirse a la Asociación de Ciudades Educadoras (creada en 1994 para, entre otros objetivos, compartir experiencias y buenas prácticas). Para ello es necesario solicitar la admisión y afirmar que se está de acuerdo con los principios rectores de la mencionada Carta.

Aunque en su mayoría se trata de ciudades de diverso tamaño, entre las poblaciones asociadas también encontramos municipios de menor tamaño, como el de Nàquera (Valencia, España), cuya población no supera los seis mil habitantes. Es necesario porque, en los municipios, se considera que el capital social está más presente (Falk and Kilpatrick, 2000), entendiendo como tal las redes de interacción mutua y estables en el tiempo (Bourdieu, 2011).

Desde la perspectiva de las Ciudades Educadoras se entiende que las urbes tienen impulsos educativos; y que no pueden improvisar en materia de educación, sino que deben hacer un plan establecido previamente. Esto se debe a que, desde ese prisma, se considera que las ciudades tienen incontables posibilidades educadoras. Estas incontables posibilidades educadoras, en ocasiones, no son percibidas por parte de la ciudadanía. Pero al establecer un plan de acción educativo se pone en valor todo ese potencial en una doble dirección: por un lado, porque descubren las herramientas y diversidad social que poseen en su interior, empoderando al municipio, cuando ponen en valor su diversidad; y por otro, porque muestra hacia el exterior sus potencialidades como contexto turístico y atractivo que visitar.

\footnotetext{
${ }^{1}$ Cristina Benlloch Domènech. Departament de Sociologia i Antropologia Social. Universitat de València. Email. Cristina.benlloch@uv.es
} 
Todos los municipios tienen cultura y largo recorrido histórico, diversidad y un tejido social, que, gracias a la Ciudad Educadora, es posible sacar a relucir, puesto que sobre la mesa educadora se sitúan todos los elementos que componen la ciudad: tanto los materiales como los inmateriales. Cuando los municipios cumplen con los principios de la Carta es posible mejorar la complejidad del municipio desde la perspectiva de las ciudades educadoras, sacando todo el partido a la ciudad y empoderándola desde la perspectiva educativa.

Desde el punto de vista de nuestro análisis, todos los asentamientos humanos tienen potencial educador si son conscientes de ello y trabajan con la perspectiva adecuada, pero quizás esto sea menos visible en los contextos rurales, de ahí que se considere pertinente hablar de ello en este espacio. Para ello es recomendable definir los puntos fuertes de cada núcleo. El objetivo principal del diagnóstico de ciudad educadora es mostrar todas esas potencialidades educadoras y darles perspectiva integral. En este sentido, la elaboración de un diagnóstico previo para comprensión de la magnitud de los agentes y recursos educadores es fundamental si se tiene como objetivo comprender la diversidad educativa del municipio en su totalidad.

Por eso, y a la vista de la Carta, se debería partir de dos elementos o herramientas educativas: los recursos educadores (elementos tangibles) y los agentes educadores (sujetos en sentido amplio).

Imagen 1. Elementos clave para el diagnóstico de ciudad educadora.

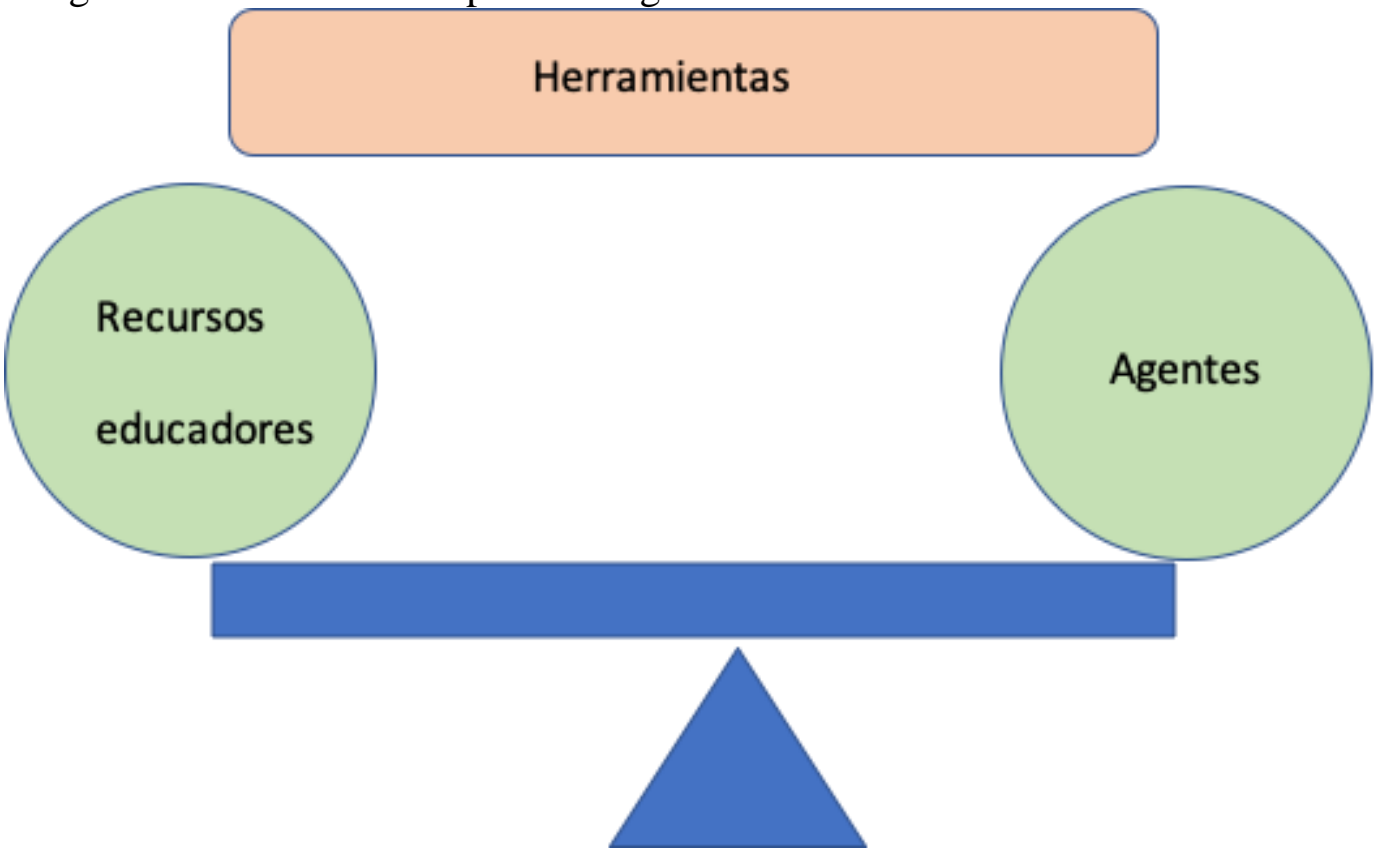

Fuente. Elaboración propia a partir de los fundamentos de la Carta.

Los municipios per se son educadoras, cuentan con una multiplicidad de recursos para llevar a cabo esta acción; solo es necesario un cambio de perspectiva y de visión sobre sí mismos. Asimismo, es necesario que las personas que residen en ellos participen de la concepción de la Ciudad Educadora, pero para ello es imprescindible un impulso político desde la Administración local. 
Imagen. Grupos de agentes implicados en la construcción de la Ciudad Educadora.

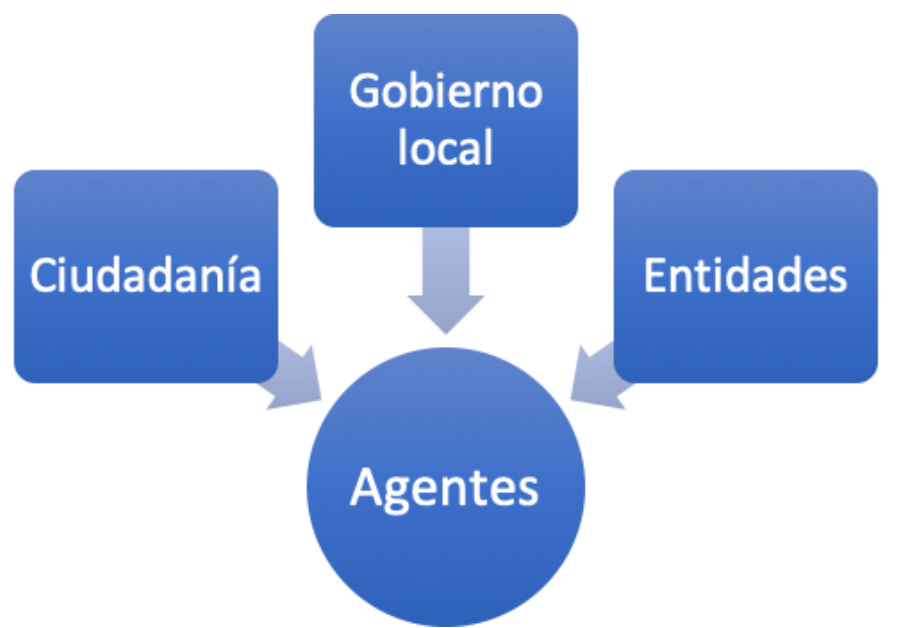

Fuente. Elaboración propia a partir de la Carta de Ciudades Educadoras.

Los actores principales en todo este proceso ciudadano educativo pueden resumirse en tres: ciudadanía, Gobierno local y entidades. Estos tres partícipes están vinculados al principio de corresponsabilidad que consiste en que todos ellos son los encargados del diseño, construcción y desarrollo de una Ciudad Educadora, buscando una ciudadanía activa.

Para llevar a cabo este plan de empoderamiento local, los municipios pueden trabajar desde un elemento que los identifique y desde el que articular las políticas y acciones sociales. Se trata de identificar aquello que es característico y sobre lo que es posible articular una identidad para general un concepto más amplio sobre el que elaborar acciones que partan de la diversidad del tejido social. Este elemento sirve para simplificar la agenda educativa, pero también para reforzar la identidad del municipio a la vez que se proyecta hacia el exterior.

Es fundamental el factor político de ejercicio, porque es la Administración quien, finalmente, tiene la decisión de lo que se hace con el espacio público, ya que es en ese lugar donde se desarrolla la vida de la Ciudad Educadora. La tarea política consiste en la construcción y reconstrucción de proyectos sociales para que el municipio sea habitable. Es una tarea fundamentalmente política, en la medida en que conecta la construcción simbólica de la ciudad con la material.

Esto ocurre porque cada persona se relaciona con otras produciendo una interconexión que se transmitirá entre generaciones. Por ello, desde el punto de vista de la Ciudad Educadora, es vital conocer la diversidad que compone la ciudad o municipio, ya que cada cultura que pasa deja su impronta, cada persona es única. Si se consiguen lazos 
fuertes, se trabaja adecuadamente sobre el capital social; puesto que uno de los fines últimos es la cohesión social.

En un momento clave para los contextos rurales, en el que la despoblación es una amenaza real, la Ciudad Educadora es una posibilidad para romper con los estereotipos que circulan en torno a ellos; puesto que hacer un diagnóstico holístico de Ciudad Educadora pone de manifiesto los puntos fuertes de los lugares. Una oportunidad de implantar políticas públicas desde una perspectiva que abarque la realidad en su totalidad.

\section{Bibliografía}

Bourdieu, Pierre. 2011. “The Forms of Capital.” In The Sociology of Economic Life, Third Edition, 78-93. New York: Taylor and Francis Inc.

Falk, Ian, and Sue Kilpatrick. 2000. "What Is Social Capital? A Study of Interaction in a Rural Community.” Sociologia Ruralis 40 (1): 87-110. https://doi.org/10.1111/1467-9523.00133. 